\title{
Uma avaliação sobre a relação multiculturalismo e educação
}

- Vera Rudge Werneck*

\begin{abstract}
Resumo
O artigo tem como objetivo a avaliação da relação entre multiculturalismo e educação. Inicia com considerações gerais sobre o tema, passando, em seguida, para a análise das noções de identidade e de cultura, categorias indispensáveis para a compreensão da noção de multiculturalismo. Conceitua então a educação como o processo que leva o educando a reconhecer, apreender e hierarquizar os valores de modo próprio e adequado para que possa situar-se no mundo como pessoa e como personalidade. Entendendo a avaliação como a análise do valor de algo com relação a um determinado referencial, vai fundamentar-se do ponto de vista filosófico na Teoria dos Valores de Max Scheler (1955) e de Yvan Gobry (1975). Do ângulo sociológico baseia-se em Tomás Tadeu da Silva $(1994,2005)$. Conclui levantando as exigências da educação com relação ao multiculturalismo e mostrando a necessidade do estabelecimento de referenciais para que se possa realizar o procedimento da avaliação dessa relação.
\end{abstract}

Palavras-chave: Multiculturalismo. Educação. Identidade. Cultura. Avaliação.

\section{An evaluation on the relationship between education and multiculturalism \\ Abstract}

The purpose of the article is to evaluate the relationship between multiculturalism and education. Initially, general considerations are made on the subject matter and, subsequently, an analysis is made of the concepts of identity and culture, which are indispensable categories for the comprehension of the concept of multiculturalism. The article goes on to conceptualize education as the procedure that causes the learner to recognize, learn and classify values in a hierarchical manner, according to learner's own method, in such a way as to enable the individual to ascertain his position in the world as a person and personality. Understanding evaluation as the analysis of the worth of something in relation to another determined point of reference and it is based on the philosophical standpoint of the Theory of Values developed by Max Scheler (1955) and Yvan Gobry (1975). From the sociological standpoint, it is based on the ideas of Tomás Tadeu da Silva (1994) (2005). The article closes with an assessment of the

* Doutora em Filosofia, Universidade Gama Filho; Professora Titular da Universidade Católica de Petrópolis. E-mail:vera.werneck@ucp.br

Ensaio: aval. pol. públ. Educ., Rio de Janeiro, v. 16, n. 60, p. 413-436, jul./set. 2008 
education requirements with regard to multiculturalism and defends the need to establish points of reference to enable an evaluation of this relationship.

Keywords: Multiculturalism. Education. Identity. Culture. Evaluation.

\section{Una evaluación sobre la relación entre multiculturalismo y educación Resumen}

El artículo tiene como objetivo la evaluación de la relación entre "multiculturalismo" y educación. Empieza con consideraciones generales cerca el tema perpasando luego al análisis de nociones de la identidad y cultura, categorías indispensables a la comprensión del "multiculturalismo". Conceptuase, entonces, la educación como el proceso que lleva al estudiante a reconocer, asegurar y jeraquizar los valores de forma propia y acomodada para que se pueda establecerse frente al mundo como persona y como personalidad. Mirando a la evaluación como el análisis de valor de alguna cosa en relación a un dado referencial, va a fundamentarse en la mirada filosófica De La Teoría de los Valores de Max Scheler (1955) y Yvan Gobry (1975). Del prisma sociológico, asenta se em Tomás Tadeu da Silva (1994, 2005). Se va a concluir alentando las exigencias de la educación en relación al "multiculturalismo" y presentado la necesidad de apuntamentos de referenciales para que se pueda hacer el provenir de la evaluación de esta relación.

Palabras clave: Multiculturalismo. Educación. Identidad. Cultura. Evaluación.

\section{O estado da questão: considerações iniciais}

Destacou-se recentemente nos jornais a notícia de uma tribo de índios no Brasil que, num esforço para resgatar a sua cultura, sistematizou o ensino de seu idioma às suas crianças. A matéria enfatizava o objetivo da conservação e da transmissão da cultura dos antepassados e apresentava uma foto de índios vestidos, segundo o seu costume com cocares, e pinturas, e relógios de pulso...

Essa imagem traz de volta a antiga e atual questão da diversidade das formas culturais e da ação transformadora da educação.

É certo que cada povo, cada grupo humano, interfere na natureza a seu modo, resolve os problemas, ultrapassa os obstáculos e desafios que ela the propõe de maneira própria e diferente. É certo, também, que a educação tem como fim a humanização do homem, o seu contínuo aprimoramento.

Evidencia-se então um paradoxo: como conciliar o respeito às peculiaridades culturais e promover a educação, transformadora por definição?

Percebem-se algumas correntes de pensamento que defendem o multiculturalismo como a aceitação de todas essas manifestações sem reflexão crítica, sem juízos de valor. Partem do pressuposto de serem todas elas igualmente válidas e de que como tais, devam ser aceitas e transmitidas às novas gerações.

Ensaio: aval. pol. públ. Educ., Rio de Janeiro, v. 16, n. 60, p. 413-436, jul./set. 2008 
Por estranho que pareça, é especialmente na área da educação que essas idéias mais se desenvolvem. Educadores, conscientes das ações autoritárias do passado em sua área, buscando redimir-se dos erros cometidos, defendem o multiculturalismo como um viés relativista aceitando todas as culturas com seus procedimentos e costumes, muitas vezes inadequados, desrespeitosos e injustos para com o ser humano.

Acentua-se a contradição: por um lado, insiste-se na tolerância, no acolhimento das diferenças, no multiculturalismo, no pluralismo de opiniões e de idéias, de modos de ser e de viver. Por outro lado, nunca foi tão forte e tão intenso o controle do Estado, tão numerosas as regras de bem viver e de bem pensar. Há normas para a nutrição ideal, para a saúde, para o relacionamento sexual, afetivo, familiar e social. Vacinas e exames obrigatórios, regras e proibições para a educação de crianças, parâmetros curriculares oficiais para o estabelecimento do currículo ideal.

Ao mesmo tempo em que se defende a admissão de diferentes culturas na escola, apregoam-se normas rígidas de comportamento, consideradas como "politicamente corretas".

Com freqüência esse "politicamente correto" entra em choque com usos e práticas culturais que são, por isso, condenadas como incompatíveis com os novos ideais da convivência humana.

Como entender tal paradoxo? Que critérios utilizar para contornar as dificuldades que acarretam?

Muito se acentua o fato da multiplicidade e da diversidade das culturas, mas pouco se fala da fundamental igualdade do ser humano, no que se refere às suas necessidades básicas. Fala-se mesmo na exigência de valorização das identidades plurais de gênero, etnias, padrões lingüísticos das sociedades multiculturais e até da necessidade de preparar professores para lidar com elas.

No entanto, é preciso considerar que a educação propõe-se à transformação da sociedade, ao desenvolvimento de suas potencialidades, ao seu crescimento moral e à sua humanização. Como conseguir esse feito, aceitando-se, ao mesmo tempo, passivamente, usos e costumes tão impróprios para atingir tal objetivo?

Mostra Tomás Tadeu da Silva (2005, p. 85) que

tornou-se lugar comum destacar a diversidade das formas culturais do mundo contemporâneo. É um fato paradoxal, entretanto que essa suposta diversidade conviva com fenômenos igualmente surpreendentes de homogeneização cultural. Ao mesmo tempo em que se tornam visíveis manifestações e expressões culturais de grupos dominados, observa-se o predomínio de formas culturais produzidas e veiculadas pelos meios de comunicação de massa, nas quais aparecem de forma destacada as produções estadunidenses.

Ensaio: aval. pol. públ. Educ., Rio de Janeiro, v. 16, n. 60, p. 413-436, jul./set. 2008 
Aqui chama ele a atenção para o que ocorre na mídia que, propondo-se a divulgar as diferentes manifestações culturais, como que as dessacraliza, deturpa e, ao mesmo tempo, contribui para a formação de uma sociedade mais homogênea porque participante das mesmas informações.

A tolerância, a complacência e a atitude de aceitação do diferente tornam-se então características culturais universais do homem da atualidade.

A indiferença ante a diversidade cultural, que é apresentada como originalidade, como bizarrice, ao ser proposta pelos meios de comunicação social, que se constitui talvez no mais forte instrumento de homogeneização cultural, revela mais um paradoxo do mundo contemporâneo.

É interessante ainda registrar a colocação de Guareschi e Biz (2005, p. 42), quando mostram que

a mídia não só diz o que existe e, conseqüentemente, o que não existe, por não ser veiculado, mas dá uma conotação valorativa de que algo é bom e verdadeiro, à realidade existente. É nessa instância que são criados e legitimados determinados valores. E são eles que nos impulsionam a agir.

Novo paradoxo: por um lado é difundida a diversidade, multiplicidade das culturas, por outro, é feito um processo de valorização e de desvalorização das suas ações, o que vai corresponder à educação e à universalização.

Percebe-se ainda a impossibilidade de frear o processo histórico. Não há solução para essa questão: o desenvolvimento da humanidade se faz de maneira pacífica ou violenta pela fusão, aglutinação, interação enfim, das produções culturais. Não há como nem por que preservar as culturas em estados "puros" "originais e intocados".

Pode-se constatar que, ao crescimento do desejo de liberdade, de democracia, de igualdade de direitos, corresponde, pela insegurança e pelas necessidades de ordem prática, a restrição à liberdade, a perda de parte dos direitos civis, a exigência de acomodação às imposições do Estado.

Todas essas contradições levam à exigência de uma maior reflexão sobre a relação educação e cultura e, mais precisamente, sobre a relação educação e diversidade cultural para que seja possível a avaliação do fenômeno. Torna-se clara a necessidade do estabelecimento de critérios de avaliação da hierarquia de valores subjacente a essas culturas, caso contrário vai-se cair simplesmente em posturas relativistas que se furtam a qualquer análise entrando-se em contradição com os próprios princípios da educação ao se aceitarem injustiças e atitudes que desrespeitam a dignidade humana sob a desculpa de fazerem parte de determinada prática cultural.

Embora seja possível reconhecer preconceitos e posturas dogmáticas como se representassem exigências universalmente válidas sendo transmitidas e cobradas pe-

Ensaio: aval. pol. públ. Educ., Rio de Janeiro, v. 16, n. 60, p. 413-436, jul./set. 2008 
los professores, em outros casos prepondera o relativismo e a suspensão do juízo como postura ideal do educador.

É realmente considerável o risco do juízo subjetivo e arbitrário.

A própria noção de educação exige o comprometimento com o respeito à dignidade humana e com a justiça para com todos sem distinção.

O educador não pode compactuar com o erro e o mal com a justificativa de fazerem eles parte de determinada prática cultural. Não há, evidentemente, nenhuma homogeneidade cultural. Cada etnia, cada grupo social interpreta o real a seu modo, a ele atribuindo diferentes sentidos e significações.

A dificuldade situa-se exatamente na necessidade de conciliar o respeito a esses significados, às diferentes modalidades culturais com as exigências da ação educacional. É preciso aceitar e acolher a diversidade das culturas, mas não o relativismo e a demagogia que se contrapõem aos objetivos da educação.

professor, como um profissional reflexivo que se propõe ao pensamento crítico sobre a prática pedagógica, vê-se diante desse desafio: acolher e dar espaço para o desenvolvimento de manifestações multiculturais e, ao mesmo tempo, manter-se fiel aos seus objetivos educacionais.

Esse problema vai levá-lo fatalmente à busca do estabelecimento de critérios de avaliação para que possa distinguir nas culturas o que representa a satisfação das necessidades universais daquilo que expressa as peculiaridades de cada grupo social.

acolhimento tácito de todas as características culturais dos diferentes grupos sociais leva a contradições e incoerências e à abdicação da postura de educador.

É certo que o profissional de educação não pode considerar-se como o "dono da verdade" nem achar-se no direito de impor a sua própria escala de valores.

A postura crítica do professor deve levá-lo a aceitar o diferente, as diferenças e a reconhecer as situações em que essas peculiaridades podem atentar contra a saúde, o bem-estar ou a dignidade da pessoa humana.

Algumas práticas típicas de determinadas culturas são inaceitáveis pelo educador como, por exemplo, o machismo, a violência e a escravidão, os maus tratos físicos e o desrespeito ao livre arbítrio. Para que não se reforcem preconceitos e imobilismos injustificáveis não basta a abertura para as diferenças, mas é necessária a transparência dos critérios de avaliação e a clara definição dos objetivos da ação pedagógica.

O educador não tem escolha. Está comprometido com a transformação da sociedade no sentido de um aprimoramento da saúde, do conhecimento científico, do bem- estar emocional e da justiça social.

Ensaio: aval. pol. públ. Educ., Rio de Janeiro, v. 16, n. 60, p. 413-436, jul./set. 2008 
De pouco adianta uma atitude de abertura ao multiculturalismo se não se pode compactuar com nenhuma prática anti-higiênica, não saudável, anti-científica, autoritária ou anti-social.

Talvez, a questão esteja mal colocada. Ou conservadorismo e rigidez ou multiculturalismo. É falsa essa dicotomia. Não se trata de posições antagônicas e extremadas em que deve situar-se o educador, mas de perceber a necessidade do estabelecimento de critérios iniciais que possibilitem uma ação transformadora executada de modo consciente e livre a partir de um referencial previamente estabelecido e não de posturas subjetivas e arbitrárias.

O paradoxo aqui analisado manifesta-se já quando, ao defender-se multiculturalismo nas escolas, não se põe em evidência o fato de também o professor emergir de um universo cultural. Também ele foi educado segundo determinados padrões culturais que devem, de certo modo, ser superados para que possa abrirse para os outros. Registre-se que as Diretrizes Curriculares de Formação do Professor (CONSELHO NACIONAL DE EDUCAÇÃO, 2002) constituem um documento que se propõe a dar orientações gerais sobre a formação docente, objetivando uma uniformização do comportamento dos profissionais da área.

As sociedades manifestam-se como multiculturais, plurais e desiguais. $\bigcirc$ multiculturalismo vai então valorizar essa diversidade cultural que, no passado, foi praticamente ignorada e vítima de preconceitos e condenações tácitas.

Não se pode ignorar que certos hábitos de alimentação, de administração, do tempo, de exploração predatória da natureza que mais se explicam pela pobreza, pela adversidade das condições do meio ambiente, pela doença do que pelas características culturais foram registrados como desigualdade no sentido de inferioridade.

É difícil a posição do educador: acatar o pluralismo cultural e ao mesmo tempo não se manter passivo diante de todas essas mazelas sem procurar combatê-las e tentar transformá-las, classificando-as como manifestações culturais. Por outro lado, que direito ele tem de condenar características culturais que não causam prejuízos, que não desrespeitam nenhum valor básico da pessoa humana por serem elas próprias de culturas diferentes da sua?

Todas essas questões remetem sempre para a necessidade da busca de critérios de avaliação que permitam a superação do subjetivismo e do relativismo, não levando a discriminações e condenações, mas ajudando na promoção do aprimoramento humano.

As ações afirmativas que buscam reparações de injustiças se fundamentam em valores universais como justiça, respeito e igualdade. $\bigcirc$ multiculturalismo não pode então ser entendido simplesmente como a aceitação de todas as características das diferentes culturas, mas como a necessidade do estabelecimento de critérios de avaliação das exigências fundamentais da pessoa humana.

Ensaio: aval. pol. públ. Educ., Rio de Janeiro, v. 16, n. 60, p. 413-436, jul./set. 2008 
Somente a partir dessa postura vai-se dar a abertura nos currículos escolares para as diferentes expressões culturais, resguardando-se o que não pode ser deixado de lado.

Os Parâmetros Curriculares Nacionais (PCNs) (1997), ao incluírem a diversidade cultural em seus eixos, procuram situar-se fora de qualquer cultura partindo das exigências universais do ser humano.

As ações afirmativas não são desenvolvidas a partir do acatamento ao multiculturalismo, já que o legislador é sempre alguém situado numa cultura que seria então a dominante, mas do reconhecimento de comportamentos de valor universal e transcultural como o respeito pela pessoa humana e a exigência da justiça.

Sejam ações reparadoras ou preventivas, a motivação que as justificam paira sempre acima das diferenças culturais. A própria constatação e a tentativa de superação e de compensação das relações de poder já implicam uma postura de reconhecimento de valores universais.

A pluralidade e a diversidade das culturas não se opõem ao progresso da ciência. A ciência e a tecnologia buscam o que pode ser globalmente aceito. Embora possam elas adaptarem-se às características de cada povo, de cada cultura fundamentam-se sempre no que se apresenta como necessário para todos.

Complexa é então a posição das instituições de ensino, tendo que, ao mesmo tempo, promover a ciência e desenvolver a tecnologia que se baseiam no universal, e respeitar e valorizar a produção cultural dos diferentes grupos com os quais vai lidar.

Não se concebe uma ciência diversificada e própria para cada grupo social. $\bigcirc$ conhecimento científico pretende ser universalmente válido mesmo quando diversificado. Note-se que validade universal não significa uniformidade. Embora sejam inúmeros os caminhos para o conhecimento do real, o objetivo primordial da ciência, todos eles precisam ter validade universal nas circunstâncias devidas. Ao contrário de outras áreas da cultura como a artística, por exemplo, que é própria de cada grupo social, a científica, embora múltipla, vale para todos eles.

Pode ser bastante esclarecedora a explicação da ciência pela comparação com uma esfera em cujo centro estivesse o objeto do conhecimento. Cada ponto dessa esfera constituiria um foco de observação do real, a partir do qual se construiria o conhecimento. Haveria uma grande diversificação a partir do ponto de vista do sujeito em relação ao objeto, mas uma validade universal levando-se em consideração esse posicionamento. Haveria, portanto, uma relatividade no conhecimento, mas não um relativismo.

relativismo caracteriza-se por ligar o conhecimento ao interesse do próprio sujeito e não com o objeto. A arte, tomada como exemplo, expressa a sensibilidade do sujeito no modo de tratar o concreto. Manifesta o pessoal, o peculiar, o próprio de cada um e de cada grupo social. A moda, a maneira de preparar os alimentos, a regulamentação do convívio social entre outras expressões culturais são particulares

Ensaio: aval. pol. públ. Educ., Rio de Janeiro, v. 16, n. 60, p. 413-436, jul./set. 2008 
e próprias de cada grupamento da sociedade. A ciência e a tecnologia, ao contrário, embora se manifestem de diferentes modos, são universais.

Não cabe então a tentativa de particularizar a ciência nem de universalizar as expressões culturais particulares, mas sim de respeitar o espaço de cada uma.

A escola enfrenta esse grande desafio: conciliar o universal e o particular, o global e o regional.

Evidencia-se então outro paradoxo na área educacional: luta-se, ao mesmo tempo, com o apoio da legislação de ensino, pelo respeito ao multiculturalismo e pela homogeneização cultural que se inicia com a obrigatoriedade da alfabetização.

Essa reflexão inicial sobre os paradoxos, com que se defronta o profissional da educação, leva à exigência de algumas colocações filosóficas.

O artigo tem então como objetivo refletir sobre a relação entre multiculturalismo e educação. Inicia com considerações gerais sobre a questão passando em seguida para a análise das noções de identidade, cultura e multiculturalismo. Fundamentando-se teoricamente do ponto de vista filosófico em Scheler (1955) e Gobry (1975) e do ângulo sociológico em Silva (1994, 2005), vai concluir levantando as exigências da educação em relação ao multiculturalismo e mostrando a necessidade do estabelecimento de referenciais de avaliação.

\section{Dois pontos de vista, duas perspectivas para o estudo da identidade}

Para que seja possível prosseguir com a reflexão proposta deve-se antes de mais nada distinguir as perspectivas, segundo as quais será analisada a questão.

Mostra Tomás Tadeu da Silva (1994, p. 90), que "é preciso distinguir entre um problema sociológico da educação e um problema educacional, entre uma perspectiva analítica e uma perspectiva normativa". A educação é uma ciência normativa. Ela não quer saber como as coisas são, mas como deveriam ser. Embora na sua prática possa valer-se das pesquisas sobre os fatos, seu objetivo primeiro é o aprimoramento do homem, a promoção de um mundo melhor. A filosofia da educação vai, portanto, fundamentando- se na antropologia filosófica, buscar saber o que pode corresponder às necessidades fundamentais do homem e o melhor modo de satisfazê-las.

A sociologia parte de outra perspectiva. Ela procura conhecer a situação atual da Educação, as causas, os efeitos e as circunstâncias dos fatos a ela vinculados.

Novamente apelando para Silva (1994, p. 90), encontra-se:

A sociologia da Educação não está normativamente preocupada com as finalidades da educação, com a natureza do conhecimento educacional, com as melhores formas de organizar o sistema educa-

Ensaio: aval. pol. públ. Educ., Rio de Janeiro, v. 16, n. 60, p. 413-436, jul./set. 2008 
cional ou de desenvolver melhores métodos de ensino ou de avaliação embora todas essas preocupações sejam legítimas e possam ser iluminadas por meio das contribuições da Sociologia da Educação, está preocupada, em vez disso, em compreender como a educação implica a constituição da sociedade, na constituição da estrutura social e do sujeito social. A Sociologia da Educação está preocupada em compreender de que forma a educação institucionalizada está envolvida na dinâmica social e quais são suas relações mútuas.

Numa reflexão sobre a Educação as duas perspectivas devem ser contempladas. Não se pode deixar de lado o ângulo filosófico sem o qual não se estabelecem objetivos, metas e referenciais de avaliação.

O ato de avaliar exige uma postura filosófica. Avaliar significa analisar o valor de algo em relação a alguma carência ou algum anseio humano. Não é então possível avaliar sem um referencial, sem um fim em vista. Em última instância, o pólo de referência é sempre o homem e a satisfação das suas necessidades.

Percebe-se então a diferença entre avaliar e medir. A avaliação para apreender a humanidade do homem, deve ultrapassar a medida objetiva e ao mesmo tempo precaver-se contra os enganos da subjetiva. Afirma Nilson José Machado (1994, p. 9) que

[...] julgamentos de valor são sempre mais complexos do que meras operações de medição; em conseqüência, a tarefa do professor, ao avaliar mais do que saberes técnicos, exige a competência, o discernimento e o equilíbrio de um magistrado, uma vez que o que está em jogo é o pleno desenvolvimento do ser humano.

A medida expressa quantidade, enquanto a avaliação envolve um julgamento de valor e uma expressão qualitativa. A medida leva ao conhecimento de dados parciais e determinados, com relação a metas e objetivos definidos.

Mostra Ceres Santos Silva (1992, p. 11) que

avaliar deriva de valia que significa valor. Portanto, avaliação corresponde ao ato de determinar o valor de alguma coisa. A todo o momento o ser humano avalia os elementos da realidade que o cerca. A avaliação é uma operação mental que integra o seu próprio pensamento - as avaliações que faz orientam ou reorientam sua conduta.

O problema da avaliação não pode, portanto ser reduzido a procedimentos técnicos sem maior fundamentação filosófica. É um processo que começa na antropologia filosófica, continua na gnosiologia dos valores, na ética, no direito tendo sempre como pano de fundo a reflexão filosófica.

A avaliação da relação da educação com as múltiplas culturas vai, portanto, exigir, como ponto de partida, a reflexão filosófica.

Ensaio: aval. pol. públ. Educ., Rio de Janeiro, v. 16, n. 60, p. 413-436, jul./set. 2008 
Tomou-se como referencial para esta reflexão, do ponto de vista filosófico, a Teoria dos Valores.

Embora a questão do valor tenha sido contemplada desde os mais remotos tempos, de modo teórico e sistemático, o tema só começa a ser tratado no século XIX. É especialmente com Scheler (1955) e, posteriormente, já no século XX, com Gobry (1975) que a Teoria do Valor vai ser desenvolvida.

Considera-se como "valor" tudo o que vale para o homem. Tudo aquilo que pode satisfazer as suas necessidades e anseios e como "bens de valor" os objetos que portam valores.

Os valores, portanto, não são, valem. Constituem outra categoria do conhecimento do ser.

A noção de avaliação está diretamente ligada à de valor. Diferentemente de medir, ou seja, comparar tendo por base uma escala fixa, avaliar significa determinar o valor de algo.

É pelo conhecimento dos fins da tendência própria do sujeito que se pode avaliar a sua trajetória e as suas ações. Scheler (1955) faz uma distinção entre os fins da tendência e os objetivos da vontade. Os fins da tendência são os valores. $\bigcirc$ estado da carência leva naturalmente à tendência em busca dos valores que o satisfaçam e o preencham. Ele (SCHELER, 1955, p. 63) acrescenta ainda:

\footnotetext{
Nada pode tornar-se objetivo se não tiver sido anteriormente fim. $\bigcirc$ objetivo se fundamenta sobre o fim. Pode haver fins sem objetivo, mas nenhum objetivo sem um fim previamente dado. Não podemos criar um objetivo "ex nihilo" nem assinalá-lo sem uma "tendência" prévia para alguma coisa.
}

Cabe à Filosofia da Educação conhecer os seus fins e à Sociologia analisar em que medida os objetivos, as metas, as práticas, o sistema educacional, enfim, estão sendo implementados.

A análise da questão do multiculturalismo deve começar pela questão da identidade. A identidade individual e dos diferentes grupos sociais.

A primeira constatação é a de ser identidade um termo análogo, isto é, um conceito com significados semelhantes, mas não idênticos. Um conceito que segundo o "Dicionário de Filosofia", de Nicola Abbagnano (2000, p. 528), pode ter três definições fundamentais: $1^{\circ}$ ) como unidade de substância, $2^{\circ}$ ) como possibilidade de substituição, $3^{\circ}$ ) como convenção.

Do ponto de vista filosófico, identidade vai ser então aquilo que caracteriza o ente. Aquilo que diz o que ele é. Do ângulo da sociologia, é algo mutável, variável de época para época. Afirma Stuart Hall (2002, p. 12) que "o sujeito previamente 
vivido como tendo uma identidade unificada e estável está- se tornando fragmentado, composto não de uma única, mas de várias identidades, algumas vezes contraditórias ou não resolvidas".

Essa parece ser a primeira grande dificuldade da questão da identidade: trabaIhar com um conceito análogo sem o devido esclarecimento do sentido em que está sendo tomado.

Do ângulo filosófico a identidade é o que resulta da própria substância do ser e o que estabelece o seu fim. É o que é próprio do sujeito e o que o caracteriza enquanto tal. $\bigcirc$ que diz o que o ser é.

Do ponto de vista sociológico é o que caracteriza o sujeito num tempo e num espaço. É o conjunto de características acidentais e variáveis que num determinado período o identifica.

Por diversas que sejam as "posições" do sujeito numa sociedade, por variados que sejam os seus papéis sociais, as suas necessidades fundamentais continuam as mesmas, ou seja, a sua identidade enquanto "pessoa" continua a mesma. A grande mudança está no fato de ela não mais ser considerada como algo pronto no nascimento apenas em estado de potência a ser atualizada, mas como uma grande carência a ser preenchida. Essa "necessidade", essa "carência" fundamental que se manifesta em múltiplas necessidades específicas deve ser satisfeita por aquilo que a ela corresponda, ou seja, o "valor". Admitindo-se como valor o que de algum modo vale para o homem, pode-se entender a sua identidade como o resultado da apreensão de uma série hierarquizada de valores. Nesse sentido, o sujeito tende para o valor como para o seu fim específico e a apreensão dos valores passa a ser o seu objetivo fundamental da vida.

Esse entendimento parece confirmar-se quando, contrariamente a toda essa aparente diversificação das "identidades" do mundo pós-moderno, há uma luta comum pela universalização dos valores fundamentais do homem. É então que se compreende Gobry (1975) quando mostra que a carência humana não é ontológica mas axiológica.

Os papéis sociais que marcam as identidades culturais podem ser sim, cada vez mais provisórios, variáveis e problemáticos, mas não as necessidades humanas fundamentais que estão progressivamente mais explícitas, universais e exigentes. A necessidade de saúde, conhecimento, liberdade, respeito, justiça e vida afetiva é cada vez mais reconhecida como direito humano que deve ser estendido a todos.

Há, portanto, uma contradição entre a afirmação da diversificação das identidades e a exigência da universalização dos direitos humanos, o que pressupõe uma igualdade essencial.

Nesse sentido pode-se dizer que o sujeito pós-moderno, como o de qualquer período histórico, tem a mesma identidade embora não tenha tido suas necessidades sempre reconhecidas.

Ensaio: aval. pol. públ. Educ., Rio de Janeiro, v. 16, n. 60, p. 413-436, jul./set. 2008 
Sob essa ótica toma um novo sentido a afirmação de Hall (2002, p. 38) de que

a identidade é realmente algo formado ao longo do tempo, através de processos inconscientes, e não algo imanente, existente na consciência no momento do nascimento. Existe sempre algo 'imaginário' ou fantasiado sobre sua unidade. Ela permanece sempre incompleta, está sempre 'em processo', sempre "sendo formada",

e,

assim, em vez de falar da identidade como uma coisa acabada, deveríamos falar de identificação, e vê-la como um processo em andamento. A identidade surge não tanto da plenitude da identidade que já está dentro de nós como indivíduos, mas de uma falta de inteireza que é 'preenchida' a partir de nosso exterior, pelas formas através das quais nós imaginamos ser vistos pelos outros. (HALL, 2002, p. 39).

Considera-se aqui o método segundo o qual se constitui a identidade, mas não o objeto a ser conquistado. $\bigcirc$ "preenchimento" da falta não pode ser feito aleatoriamente, mas com aquilo que the é próprio, ou seja, com o valor do qual é ela carente.

Novamente apresenta-se como primordial a busca dos critérios, dos referenciais que permitam o conhecimento das necessidades e dos valores fundamentais para a constituição da "identidade humana".

Pode-se então reconhecer na multiplicidade dos códigos culturais, na variedade dos estilos no acatamento das diferenças, uma caminhada em busca dos valores universais do respeito e da justiça que caracterizam a identidade humana.

Hoje há uma grande preocupação em se negar o que comumente se designa como concepção humanista tradicional caracterizada pela visão essencialista de homem. O ser humano seria aí entendido como constituído por uma essência imutável cabendo à educação promover a "atualização" dessa "potência" em termos aristotélicos. A própria idéia de natureza humana negada por Sartre na sua famosa obra "O Existencialismo é um Humanismo" seria uma manifestação dessa "essência" que distinguiria o homem do resto da natureza. Para essa corrente de pensamento as potencialidades estariam contidas a priori e definitivamente na essência devendo ser "realizadas" pela ação educacional.

Sob a influência do Existencialismo e de outras correntes modernas para as quais a existência precede a essência não havendo natureza humana, o ser do homem é mutável devendo ser construído ao longo da vida. Há então uma grande disponibilidade, uma total indeterminação devendo as identidades serem construídas sem referências estabelecidas.

Ao que parece, a questão assim colocada traz dificuldades para o educador. É interessante a afirmação de Bauman (2005, p. 32):

Ensaio: aval. pol. públ. Educ., Rio de Janeiro, v. 16, n. 60, p. 413-436, jul./set. 2008 
É nisso que nós, habitantes do líquido mundo moderno, somos diferentes. Buscamos, construímos e mantemos as referências comunais de nossas identidades em movimento - lutamos para nos juntarmos aos grupos igualmente móveis e velozes por um momento, mas não por muito tempo.

E acrescenta: "no admirável mundo novo das oportunidades fugazes e das seguranças frágeis, as identidades ao estilo antigo, rígidas e inegociáveis, simplesmente não funcionam." (BAUMAN, 2005, p. 33).

Do ponto de vista da educação, diante desse fato, chega-se a uma situação de contradição. Ao mesmo tempo em que se proclama a total liberdade e a indeterminação na construção das identidades, prescreve-se uma série de regras de bem viver propõe-se um sem número de ideais educacionais. Quer-se um aperfeiçoamento contínuo dos professores quando ao mesmo tempo declara-se a inexistência de um fim para o homem e assim, a impossibilidade do conhecimento da educação ideal.

Ao mesmo tempo em que se nega a possibilidade da natureza humana, em que se defende a admissão de qualquer tipo de identidade, criticam-se modos de viver, abrem-se faculdades de educação, fala-se de currículos melhores e piores sem especificar-se o referencial utilizado.

Pode-se admitir que a questão esteja deslocada. Não se trata de confrontar teorias, essencialismo $x$ existencialismo, natureza humana $x$ indeterminação total. $\bigcirc$ que não se pode deixar de reconhecer é a existência no homem de necessidades universais e conseqüentemente, de valores universais capazes de satisfazê-las. As necessidades de vida, de saúde, de conhecimento, de liberdade e de vida afetiva são e devem ser universais. É inconcebível, como já se aceitou no passado, por interesses de dominação, que alguns grupos sociais possam ser exterminados, que não tenham direito à saúde, ao conhecimento, ao exercício do livre arbítrio e da vida afetiva.

Reconhecendo-se essas carências e esses valores como universais pode-se não estar admitindo nenhuma "essência" ou "natureza humana", mas está-se aceitando algo que caracteriza o homem, a sua "humanidade", como fundamental e que norteia e justifica a ação educativa.

Mesmo quando se restringe todo o conhecimento educacional à área da sociologia da educação não se foge dessa dificuldade. As análises dos dados das pesquisas que ajudam a programação dos currículos e projetos pedagógicos são sempre feitas tendo em vista esses referenciais.

A educação trabalha com ideais, com objetivos, com metas. A sociologia da educação vai medir e avaliar os resultados alcançados. Não há como negar essa realidade. A liberdade limita-se às diferenças e peculiaridades próprias das personalidades, mas não quanto aos valores fundamentais. É, portanto um paradoxo negar as necessidades fundamentais do homem e propor uma educação transformadora que lhe permita satisfazê-las. Quem transforma não o faz a esmo, o que não teria sentido, mas em relação a um fim.

Ensaio: aval. pol. públ. Educ., Rio de Janeiro, v. 16, n. 60, p. 413-436, jul./set. 2008 
Pode-se admitir a ação educacional não como atualização de potencialidades, mas mesmo como processo de construção da pessoa e da personalidade do sujeito, ou seja, como processo de construção da sua identidade será preciso o estabelecimento de referenciais ideais que o direcionem. $\bigcirc$ desafio concentra-se na escolha desses critérios. No entanto, percebe-se que, mesmo variando muito, ao longo da História sempre é possível uma avaliação. Não se vai considerar a escravidão como uma prática viável somente por ter sido admitida no passado. Quando a Organização das Nações Unidas (ONU) estabelece o Índice de Desenvolvimento Humano (IDH) como referencial de avaliação, ela se fundamenta em carências e valores universais, nos ideais éticos de respeito pela vida, igualdade de direito e justiça social.

É possível então constatar, como o fazem muitos sociólogos, a velocidade das mudanças de identidade nos dias de hoje, mas não negar a possibilidade do estabelecimento de critérios de avaliação sem os quais a educação perderia o seu sentido.

Seguindo essa linha de pensamento pode-se reconhecer a prática educacional como sendo, a partir de determinados referenciais, um esforço constante para o aperfeiçoamento da humanidade.

\section{O conceito de cultura}

Para se chegar ao multiculturalismo deve-se começar pela análise da noção de cultura.

Sendo "cultura" um termo análogo vai-se encontrá-lo empregado em sentidos diferentes embora semelhantes.

Não cabe aqui a análise das suas inúmeras conceituações, pode-se, no entanto, perceber duas vertentes principais, dois grandes paradigmas que servem à tentativa de relacioná-lo com a noção de educação.

Cultura seria, numa primeira acepção, o resultado de toda e qualquer interferência humana na natureza, no outro ou em si mesmo. Seria a modificação causada pela ação humana que alteraria o modo de ser natural independente do valor ou contravalor que the fosse agregado.

É esta a conceituação mais aceita: a cultura como um novo modo de ser, como um costume. Fala-se em cultura com referência à prática das artes, por exemplo, e em cultura da violência como a prática usual de atos de agressão.

Nesse sentido, a cultura poderia colaborar ou não com a educação. Poderia ser uma expressão da educação ou de comportamentos anti-sociais.

A segunda vertente entende a cultura como o resultado da instauração de valor na natureza, no outro ou em si mesmo feita pela ação humana.

Nesse sentido, somente seria aceita como cultura a modificação da natureza, do outro ou do próprio sujeito que manifestasse a inserção de um novo valor.

Ensaio: aval. pol. públ. Educ., Rio de Janeiro, v. 16, n. 60, p. 413-436, jul./set. 2008 
Entendendo-se por valor tudo o que, de algum modo corresponda às necessidades do sujeito, a cultura representaria uma adaptação da natureza aos anseios do homem.

Sob esse prisma, seria a cultura, ao mesmo tempo, resultado da educação e da instrução e agente de educação e de instrução.

Pode-se fazer uma distinção entre esses dois modos de aprimoramento humano e considerar como instrução o processo de aquisição/construção de conhecimentos que leve pela sua incorporação, à capacidade de avaliação e de sua utilização de maneira adequada.

Por educação vai-se entender o processo de reconhecimento, busca, apreensão e hierarquização dos valores de modo próprio e adequado à realização humana como pessoa e como personalidade.

A cultura abrange ambas as áreas: ela é fonte de instrução, de aquisição de conhecimento e, também, de educação, já que propõe modelos e escalas de valor.

As manifestações culturais não são neutras. Pela simples apresentação estão carregadas de informações aceitas ou condenadas pela ciência, que traduzem conhecimento, erros ou noções distorcidas. Também, quanto aos valores, as produções da cultura não são imparciais. Elas expressam valores, o que vale para o homem, o que o aprimora e aperfeiçoa ou o que o avilta e degrada.

A cultura constitui então um agente de instrução e de educação não sendo jamais neutra e indiferente.

Mostra-se aí um novo paradoxo: por que tanta reflexão e regulamentação na área da educação visando à melhoria do ser humano e nenhuma na instância da cultura que também deve visar ao mesmo fim só que por caminhos diversos?

Cada vez mais se percebe que o processo de aprendizagem não se limita ao ensino recebido na escola formal, mas que é muito mais abrangente, incluindo como fontes de aprendizagem, o meio ambiente, o meio social e especialmente a mídia.

Os meios de comunicação social, como expressão cultural, podem ser considerados como uma nova modalidade de escola capaz de proporcionar o ensino das diversas disciplinas, utilizando uma tecnologia mais avançada e tendo acesso aos conhecimentos mais atualizados.

A cultura é a expressão primeiramente da satisfação das necessidades fundamentais que constituem a identidade fundamental do homem: o estado da saúde, o nível de instrução, a possibilidade de escolha do modo de viver, o acesso às condições básicas de bem-estar e de bens de consumo. Ao mesmo tempo, manifesta também o que se pode entender como a sua "identidade secundária", o seu modo peculiar de relacionar-se com o meio ambiente e com o meio social.

Ensaio: aval. pol. públ. Educ., Rio de Janeiro, v. 16, n. 60, p. 413-436, jul./set. 2008 
Colocando-se a questão desse modo, podem ser entendidos os instrumentos de medida das instituições oficiais, como a ONU, que se propõem a conhecer o desenvolvimento cultural dos países, o nível de liberdade do povo pelo exercício da democracia, o adiantamento do sistema de ensino, das condições básicas de higiene, rede de abastecimento de água, de esgoto, de energia elétrica e, ainda, aceitar e respeitar a grande diversidade cultural.

Recentemente leu-se nos jornais a notícia de que o Brasil teria perdido seis posições caindo para o $72^{\circ}$ lugar entre 131 nações no ranking global de competitividade divulgado pelo Fórum Econômico Mundial. O país teria sido prejudicado por excesso de burocracia, corrupção e impostos elevados.

Essa análise implica a existência de um critério de avaliação que considera tais características como contravalores por dificultarem a satisfação das necessidades humanas e não como aspectos da cultura brasileira a serem respeitados e transmitidos à nova geração.

A interferência humana na natureza e no próprio homem pode ocorrer de dois modos. Pode agregar valor, contribuir para a satisfação de suas necessidades ou instaurar o contravalor dificultando o seu desenvolvimento ou mesmo prejudicandoo gravemente.

Quando se fala em cultura da violência, cultura da morte está-se referindo ao hábito da violência, à banalização da morte provocada pela continuidade de sua prática.

O termo cultura dissociado da noção de valor leva à dificuldade ou até mesmo à impossibilidade de estabelecimento de critérios de avaliação e, assim, à tácita necessidade de se aceitarem todas as atitudes e todos os comportamentos humanos como culturais. Como já foi dito, avaliar significa exatamente verificar o valor de algo.

A postura, freqüentemente encontrada, que considera qualquer tipo de análise ou de avaliação como preconceituosa invalida a pesquisa e dificulta o aprimoramento da prática pedagógica.

\section{A questão do multiculturalismo}

A avaliação do fenômeno do multiculturalismo nos dias atuais constitui um grande desafio e ao mesmo tempo, uma necessidade.

Segundo Moreira e Candau (2008, p. 7): "Quer usado como meta, conceito, atitude, estratégia ou valor, o multiculturalismo costuma referir-se às intensas mudanças demográficas e culturais que têm "conturbado" as sociedades contemporâneas." Como movimento social o multiculturalismo está ligado à tomada de consciência do direito à identidade e à inadmissão de qualquer modo de discriminação social.

Como mostra Candau (2002, p. 74),

Ensaio: aval. pol. públ. Educ., Rio de Janeiro, v. 16, n. 60, p. 413-436, jul./set. 2008 
multiculturalismo é outro termo importante e polissêmico cujo sentido aprofundar para podermos nos aproximar das questões relativas às articulações entre educação e cultura(s). Configura-se como termo amplo e polêmico, uma vez que pode ser entendido a partir de diferentes perspectivas. Não há consenso na literatura disponível, embora a maior parte dos autores proponha uma 'análise semântica' para tentar esclarecer o conflito conceitual entre prefixos como multi, pluri, inter e trans. É importante, portanto, ao tratarmos de multiculturalismo, conhecer as diferentes interpretações desta expressão, entendendo até que ponto se assemelham e em que medida se contrapõem.

Em linhas gerais o multiculturalismo pode consistir na justaposição ou presença de várias culturas em uma mesma sociedade e também na relação entre elas.

Segundo Carlos Alberto Torres (2001, p. 196), "o multiculruralismo é uma orientação filosófica, teórica e política que não se restringe à reforma escolar e que aborda o tema das relações de raça, sexo e classe na grande sociedade".

Enquanto expressando uma concepção de um modo ideal de relacionamento pode ser considerado como uma ideologia já que se apresenta como uma interpretação dos papéis e das relações sociais.

A partir de princípios filosófico-religiosos que reconhecem a igualdade dos seres humanos chega-se à exigência de respeito aos direitos individuais e de liberdade nas manifestações culturais.

De acordo com os períodos históricos e com as condições ambientais e econômicas, o valor foi instaurado na natureza de diversas maneiras, dando origem às múltiplas culturas com suas peculiaridades e características próprias.

Desde que a intervenção humana tenha promovido a instauração do valor e não do contravalor, do que vale para ele e não do que the é prejudicial, todas as produções culturais são igualmente válidas. $\bigcirc$ processo de instauração do valor no concreto pode ocorrer de diferentes formas e segundo diversos paradigmas. A expressão artística do Renascimento não é melhor nem pior do que a Medieval ou a da Idade Moderna. Não tem sentido esse julgamento. Do mesmo modo, também, a manifestação cultural européia não pode por si só ser considerada superior nem inferior a qualquer outra.

Todas as expressões da cultura, enquanto resultados da instauração do valor são igualmente válidas, podendo-se apenas hierarquizá-las, tomando-se como referencial a maior capacidade de satisfação das necessidades humanas.

O multiculturalismo é, portanto, um movimento social que leva ao reconhecimento da diversidade das culturas e à investigação sobre as questões da identidade, dos direitos humanos, da exigência da tolerância entre os povos.

Ensaio: aval. pol. públ. Educ., Rio de Janeiro, v. 16, n. 60, p. 413-436, jul./set. 2008 
Obstáculo maior vem da conceituação de cultura como o produto de qualquer interferência humana na natureza, no outro ou em si mesmo. Nesse caso, perde-se a possibilidade da busca de referencial de avaliação, ficando praticamente impossível a educação.

Muitas vezes, classifica-se como preconceito qualquer crítica a algum comportamento ou produção tida como cultural. A condenação a algum uso, hábito ou costume de uma cultura é taxada freqüentemente de "preconceito", "moralismo" ou atitude politicamente incorreta.

termo preconceito significa a tomada de posição anterior ao conhecimento do objeto, anterior à conceituação. No entanto, do momento em que se pode argumentar, justificar teoricamente o conhecimento, já não se pode classificá-lo como preconceituoso.

O preconceito é uma manifestação ideológica originária do imaginário que revela uma interpretação do sujeito centrada nele próprio e praticamente desvinculada do objeto. Evidentemente, todo conhecimento resulta de uma construção mental do sujeito sobre o objeto a partir do seu ponto de vista. É possível, todavia, a distinção entre o preconceito e a conceituação justificada.

Moralismo, ao contrário de moralidade, seria a forma preconceituosa de tratar a moral. É a atitude relativista centrada no sujeito que critica sem justificar, sem dar razões para a sua afirmação.

A atitude "politicamente correta" é a que toma como referencial não o princípio da moralidade, do bem comum, mas a interpretação que melhor atenda às convenções e aos interesses políticos.

A consciência do pluralismo cultural se, por um lado, dificultou o estabelecimento de referenciais de avaliação levando à tolerância para as práticas desumanas com a justificativa de representarem expressões culturais como a violência, a escravidão, a destruição da natureza, por outro conduziu ao reexame dos procedimentos das culturas dominantes.

Atitudes e comportamentos injustificáveis que expressavam somente posturas de dominação foram criticados e condenados.

A nova visão de mundo que reconhece e aceita o multiculturalismo pode levar à reflexão sobre as necessidades fundamentais do homem e, ao mesmo tempo, ao respeito aos diferentes modos de produção cultural da humanidade.

\section{Considerações finais: a relação educação x multiculturalismo}

Para esta reflexão, partiu-se de um problema inicial: como avaliar a ação da educação sempre transformadora e a exigência do respeito ao multiculturalismo, à

Ensaio: aval. pol. públ. Educ., Rio de Janeiro, v. 16, n. 60, p. 413-436, jul./set. 2008 
diversidade cultural? Como avaliar o direito à preservação das culturas com a necessidade de aprimoramento humano, objetivo primordial da educação?

Percebe-se ser constante no homem a necessidade de aperfeiçoamento e não de simples mudança, o que explica e justifica a educação.

Mesmo os que consideram ser a educação relativa ao momento histórico variando de época para época, não conseguem separá-la do princípio da moralidade que diz que se deve fazer o bem e evitar o mal. Nenhuma proposta pedagógica em nenhum período histórico aceitou que se visasse ao mal na teoria mesmo quando na prática agiu-se contra o ser humano. As discordâncias davam-se na especificação, na determinação do que fosse o "bem" para o educando nas diferentes circunstâncias.

Ao contrário dos animais que vão cumprindo as etapas do seu desenvolvimento de modo determinado, o homem conhece-se como incompleto, imperfeito, em busca constante de aprimoramento. Esse é o fundamento da educação sem o qual ela não se justifica. Relativizar a educação é acabar com a sua razão de ser. $\bigcirc$ educador não pode agir arbitrariamente segundo interesses pessoais, modismos ou determinações de governos, mas fundamentado numa teoria que toma como referencial para sua prática pedagógica.

A negação da possibilidade de aperfeiçoamento, em relação a um referencial adotado, leva à negação da própria educação.

As práticas pedagógicas podem variar no tempo e no espaço, mas o objetivo do aperfeiçoamento contínuo, da busca de plenitude, é sempre constante.

As tribos indígenas ou africanas, os povos asiáticos ou os norte-americanos desejam sempre que as suas crianças se desenvolvam em relação a um objetivo proposto que é considerado como decorrente do fim próprio do ser humano.

A par disso, o educador percebe, também, que esse aperfeiçoamento deve dar-se não apenas em relação a um dos aspectos constitutivos do sujeito, mas a todos eles. Percebe a exigência da totalidade. De pouco adianta o aperfeiçoamento, ou seja, a educação de uma das faces de sua personalidade. $\bigcirc$ que realmente importa é a harmonia do desenvolvimento que vai levar à humanização do homem.

Evidencia-se então novamente o problema já focalizado: como dar ênfase às diferenças culturais e, ao mesmo tempo, promover o direito de igualdade na educação. Esta avaliação é um obstáculo instigante para o educador.

Já se viu que o progresso da ciência leva a uma grande regulamentação do modo de viver: como alimentar-se corretamente, como planejar a família com a sua dimensão ideal, como construir a moradia, como cuidar da saúde e dos filhos, a importância de praticar esportes, etc. Tais conselhos, embora muitas vezes apareçam como modismos, na maioria das vezes apresentam-se com justificativas científicas, tornando-se impositivos para a educação apesar de contrários a muitas práticas tidas como culturais.

Ensaio: aval. pol. públ. Educ., Rio de Janeiro, v. 16, n. 60, p. 413-436, jul./set. 2008 
São comuns as conceituações da educação como processo de crescimento decorrente da experiência e da aprendizagem visando à maior integração, adaptação e eficiência individual em relação ao grupo cultural. Essa compreensão da educação por tomar como referências apenas o grau de conhecimento e o meio social, vai trazer algumas dificuldades. $\bigcirc$ processo de integração do delinqüente em seu grupo social, a sua adaptação a contravalores e a sua maior eficiência na prática do mal não podem ser considerados como educação. As idéias de aperfeiçoamento e de aprimoramento exigem a especificação dos valores em relação aos quais elas ocorreriam.

A mesma dificuldade aparece quando se considera a educação como um processo de perpetuação das culturas, como um meio de transmissão de determinadas visões do mundo e do homem para a geração seguinte. Os contravalores como parte das culturas também seriam passados deixando a educação de ter a sua função de ação transformadora.

Usos culturais como o cigarro, a queimada, a escravidão entre outros não podem ser aprovados nem estimulados pela educação.

Por outro lado, ao mesmo tempo em que se dá atualmente uma grande ênfase ao indivíduo, ao respeito à diversidade de identidades, ao pluralismo cultural acontece o forte movimento da globalização.

Simultaneamente pretende-se reforçar as línguas regionais e aceita-se o inglês como idioma universal, primeira exigência do mundo globalizado, como condição para a uniformidade na compreensão dos mecanismos dos bens utilitários produzidos pela tecnologia.

Mostra Mike Featherstone (1994, p. 12) que,

da mesma forma, significativos foram o aumento em número das agências e instituições internacionais, as crescentes formas globais de comunicação, a aceitação do horário global unificado, o desenvolvimento das competições esportivas e premiações em nível global, o desenvolvimento de conceitos padronizados de direito e de humanidade.

Há, portanto, especialmente graças aos avanços na área da informática e das telecomunicações dos anos 80, um enorme movimento em prol da globalização.

A mudança no sistema de comunicação propiciou ainda um reordenamento do espaço derrubando as barreiras que separavam as nações. Ocorreram então uma integração e uma uniformização cultural que desarticularam o estado na sua unidade e especificidade levando a cultura a ser transnacional e a ultrapassar as sociedades estabelecidas com novos processos de permuta, de troca de mercadorias, de informações de conhecimentos científicos e técnicos que levam à crença de ser a globalização um processo que escapa ao controle humano e traz à baila a discussão sobre o papel que cabe à educação nesse contexto.

Ensaio: aval. pol. públ. Educ., Rio de Janeiro, v. 16, n. 60, p. 413-436, jul./set. 2008 
Não se pode, no entanto, confundir globalização com aceitação do outro, com solidariedade, cumplicidade ou espírito de comunidade, objetivos da educação. É inegável que o tempo e o espaço ganham novas dimensões. A velocidade da comunicação, no entanto, por si só, não aproxima as pessoas, podendo até torná-las insensíveis e solitárias.

Os aspectos econômico, social, político e cultural ultrapassam agora as barreiras regionais e nacionais interferindo nas diversidades e peculiaridades históricas e sociais. Para alguns, essa intromissão é positiva já que promove a igualdade entre os povos. Outros, a consideram negativa, pois as diferenças e características próprias devem ser respeitadas. É evidente, no entanto, que a economia globalizada distribui seus benefícios de maneira bastante desigual.

No pensar de Ricoeur (1977, p. 92), "antes de qualquer distância crítica, pertencemos a uma história, a uma classe, a uma cultura, ou a tradições". O sentimento por ele denominado de "pertença" corresponde à necessidade humana de sentir-se pertencente a um todo social que dê segurança e proteção, que sirva de modelo e de razão para viver que leve à vivência da comunidade, mas que não corresponda à noção de unidade política.

O sentimento de pertencer a um grupo social é fundamental para o equilíbrio pessoal e social. A marginalidade, o estar fora do meio social é vivenciado pelo homem como sofrimento.

O educador não pode desconhecer os benefícios e as dificuldades decorrentes da globalização nem ignorar a necessidade de pertencimento a uma comunidade, própria do ser humano.

Mostra Bauman (2005, p. 30) que

as filiações sociais - mais ou menos herdadas - que são atribuídas aos indivíduos como definição de identidade: raça [...] gênero, país ou local de nascimento, família e classe social, agora estão-se tornando menos importantes, diluídas e alteradas nos países mais avançados do ponto de vista tecnológico e econômico. Ao mesmo tempo, há a ânsia e as tentativas de encontrar ou criar novos grupos com os quais se vivencie o pertencimento e que possam facilitar a construção da identidade.

Todas essas contradições, todos esses movimentos sociais antagônicos vão exigir do educador o estabelecimento de referenciais que balizem a sua ação e o impeçam de perder o rumo na sua prática transformadora.

Permanece, portanto a necessidade de um termo de referência que norteie todo o processo da educação e permita uma avaliação das culturas e do desenvolvimento das sociedades humanas. Permanece a busca do que realmente aprimora, aperfeiçoa e torna o homem mais humano. Embora sejam muito variadas as concepções de

Ensaio: aval. pol. públ. Educ., Rio de Janeiro, v. 16, n. 60, p. 413-436, jul./set. 2008 
homem, percebe-se que algo continua estável, imutável como realidade e como meta a ser atingida. É a constatação de que o homem não é apenas uma personalidade com características individualizantes, mas é uma pessoa, valor em si mesmo independente de outros valores.

A pessoa, ao contrário da personalidade, não é constituída por valores. Ela é, ela própria, o valor. $\bigcirc$ homem é pessoa exatamente por seu valor. Não se reduz apenas ao ser, não é somente um ente entre outros com características físicas e psíquicas, mas vale por si mesmo.

A carência de plenitude, o estado de falta, de necessidade de algo que o satisfaça, mostra ter o homem uma destinação no sentido em que é direcionado a uma meta, a chegar a uma plenitude, a plenitude de "pessoa". A grande destinação que justifica a educação seria a de chegar a ser "pessoa", ou seja, chegar ao pleno valor humano.

A pessoa, no entanto, realiza progressivamente sua destinação, se valoriza paulatinamente, cresce pouco a pouco no valor. Esse crescimento é o objetivo da educação. Sua meta é a promoção do valor pessoal no individuo.

Não se admitindo no sujeito necessidades definidas e definíveis, todo o processo da educação vai reduzir-se a um ato de violência já que imporia ao educando um conjunto de valores arbitrários.

Entendendo-se por pessoa o indivíduo dotado de racionalidade, de vontade e de afetividade vai ser necessário que o processo da educação vise primordialmente aos valores correspondentes a essas características universais: a saúde, o conhecimento, a liberdade, o amor em suas múltiplas manifestações.

Todos os diferentes grupos culturais anseiam por esses valores fundamentais que se expressam de diferentes modos.

Há um dinamismo, uma tendência natural para a conquista do valor. É dele que se utiliza a educação para propor a alimentação saudável, vestimenta e moradia higiênicas, a busca da verdade, da beleza, da justiça, da liberdade, da solidariedade entre outros valores.

O processo da educação vai não somente levar o educando a procurar o valor adequado ao crescimento da "pessoa" distinguindo onde ele se encontra, avaliando-o racionalmente pelos juízos de valor, mas ainda promover a cultura, ou seja, a instauração de valores não somente no sujeito, mas também no mundo concreto.

Cada indivíduo, além de ser uma pessoa humana, tem uma personalidade, ou seja, tem característica própria que o distingue dos seus semelhantes.

Uma proposta pedagógica precisa então não apenas focalizar a "pessoa", mas também a personalidade do sujeito, aquilo que o individualiza e que o faz diferente dos outros.

Ensaio: aval. pol. públ. Educ., Rio de Janeiro, v. 16, n. 60, p. 413-436, jul./set. 2008 
Os diferentes grupos sociais são formados por "pessoas" com diferentes "personalidades" constituindo, eles próprios, "personalidades" que os identificam: as identidades culturais.

Tendo sido consideradas as exigências primordiais da "pessoa humana", a educação pode contemplar as diferentes identidades culturais, respeitando-as e desenvolvendo-as.

Como conclusão dessa breve reflexão sobre a avaliação da relação entre a educação e o multiculturalismo, chega-se primeiramente à necessidade da busca de referenciais de avaliação como meio para que se evitem arbitrariedades e preconceitos no acatamento das peculiaridades das várias culturas. Em seguida, vai-se propor as noções de "pessoa" e de "personalidade" como referenciais para a avaliação do processo da educação nas diferentes culturas.

Caberia à educação, como objetivo principal, levar o sujeito a desenvolver-se como "pessoa" aprimorando a sua saúde, o seu bem-estar material, o seu conhecimento, a sua liberdade, a sua sensibilidade independentemente do grupo cultural a que pertencesse. Como segundo objetivo, promover as personalidades com suas peculiaridades próprias, individuais e grupais, respeitando o pluralismo cultural naquilo que não se opusesse às exigências fundamentais da pessoa humana.

\section{Referências}

ABBAGNANO, N. Dicionário de filosofia. 4. ed. Tradução por Alfredo Bosi e Ivonne Castilho Benedetti. São Paulo: Martins Fontes, 2000.

BAUMAN, Z. Identidade. Tradução Carlos Alberto Medeiros. Rio de Janeiro: Zahar, 2005.

CANDAU, V. M. (Org.). Multiculturalismo e educação: questões, tendências e perspectivas em sociedade, educação e cultura (s): questões e propostas.

Petrópolis, RJ: Vozes, 2002.

CONSElHO NACIONAL DE EDUCAÇÃO. Conselho Pleno. Resolução CNE/CP n. 1, de 18 de fevereiro de 2002. Institui as Diretrizes e Bases da Educação Nacional para a formação de professores da Educação Básica, em nível superior, curso de licenciatura, de graduação plena. Diário Oficial [da República Federativa do Brasil], Brasília, DF, 9 abr. 2002. Seção 1, p. 31.

FEATHERSTONE, M. (Coord.). Cultura global: nacionalismo, globalização e modernidade. Tradução de Attilio Brunetta. Petrópolis, RJ: Vozes, 1994.

GOBRY, Y. De la valeur. Bruxelles: Vander-Nauwelaerts, 1975.

Ensaio: aval. pol. públ. Educ., Rio de Janeiro, v. 16, n. 60, p. 413-436, jul./set. 2008 
GUARESCHI, P. A.; BIZ, O. Média, educação e cidadania: tudo o que você deve saber sobre mídia. Petrópolis, RJ: Vozes, 2005.

HALL, S. A identidade cultural na pós-modernidade. Tradução de Tomás Tadeu da Silva e Guacira Lopes Louro. 7. ed. Rio de Janeiro: DP\&A, 2002.

MACHADO, N. J. Avaliação educacional: das técnicas aos valores. Revista Psicopedagógica, São Paulo, v. 13, n. 28, p. 9-18. Jan. 1994.

MOREIRA, A. F.; CANDAU, V. M. (Org.). Multiculturalismo: diferenças culturais e práticas pedagógicas. Petrópolis, RJ: Vozes, 2008.

PARÂMETROS Curriculares Nacionais (PCNs). Brasília, DF: MEC, Secretaria de Educação Fundamental, 1997.

RICOEUR, P. Interpretação e ideologias. Tradução de Hilton Japiassu. Rio de Janeiro: F. Alves, 1977.

SCHELER, M. Le formalisme em éthique et l'éthique materiale dês valeurs: essai noveau pour fonder um personnalisme éthique. Paris: Gallimard, 1955.

SILVA, C. S. Medidas e avaliação em educação. Petrópolis: Vozes, 1992. (Educação).

SILVA, T. T. O discurso pedagógico da sociologia da educação: crítica da crítica? In: MOREIRA, A. F. B. (Org.). Conhecimento educacional e formação do professor. Campinas, SP: Papirus, 1994.

Documentos de identidade: uma introdução às teorias do currículo. Belo Horizonte: Autêntica, 2005.

TORRES, C. A. Democracia, educação e multiculturalismo. Tradução de Carlos Almeida Pereira. Petrópolis, RJ: Vozes, 2001.

WERNECK, V. R. Cultura e valor. Rio de Janeiro: Forense Universitária, 2003.

Recebido em: 27/11/2007

Aceito para publicação em: 30/07/2008

Ensaio: aval. pol. públ. Educ., Rio de Janeiro, v. 16, n. 60, p. 413-436, jul./set. 2008 